\title{
Computing system for computer analysis of monitoring data and simulation of emergencies of natural and technogenic character
}

\author{
I. V. Pavlov, D. V. Niyazgulov, D. A. Podziuban \& E. N. Pyankov \\ RFNC-VNIITF named after Academician Zababakhin, Snezhinsk, \\ Chelyabinsk region, Russia
}

\begin{abstract}
This report presents the results of work carried out on the creation of the Computing system of the Regional Situational Center, which integrates information, mathematical and methodical means for computer simulation of emergency situations and analysis of monitoring data. Briefly described is the basic functionality of the developed software on the whole and constituent subsystems in particular.

Keywords: a situational center, a geoinformation system, simulation of ES, monitoring, risk assessment.
\end{abstract}

\section{Introduction}

Natural and technogenic risks that lead to emergency situations are currently some of the main dangers and hazards for mankind. The Ural region is unique throughout the world regarding its richness in objects of the atomic industry and other industrial objects, where potential accidents can lead to serious environmental contamination. According to the results of investigations carried out by Minpriroda specialists, "Chelyabinsk region refers to 2 groups of territories of 7 groups (being third after Sverdlovsk and Kemerovo regions), the population of which is subject to high technogenic load. Some 600-800 thousand people live here under the conditions of elevated ecological risk".

Scientists and specialists from the Russian Federal Nuclear Center - AllRussian Scientific and Research Institute of Technical Physics named after Academician E.I. Zababakhin (RFNC-VNIITF) with the assistance of the International Scientific and Research Center (ISTC, Moscow), developed the 
Computing system of the Regional Situational Center (SC), which integrates the software for the preparation of well-grounded recommendations and practical solutions under emergencies at potentially dangerous objects of the Ural region. The creation of the computing system in Snezhinsk is caused by a number of objective reasons:

Created in Snezhinsk, is the Emergency and Technical Center (ETC). It is a professional, qualified emergency formation on a federal level included into emergency and rescue formations of the RF Agency on Atomic Energy, with a complete staff of qualified specialists. It is equipped with the most up-to-date equipment furnished by intergovernmental agreements.

- Concentrated in RFNC-VNIITF is a rather large scientific and technical potential of scientists and specialists, accumulated in an extensive material in the field of ecological programs and ecological policy. Developed were several AWSs, which are currently applied in regional and district structures.

- Administrations of Snezhinsk and RFNC-VNIITF closely interact with regional ecological structures regarding the conduction of ecological programs.

- Closeness and equidistance from Snezhinsk of such industrial centers as Chelyabinsk and Ekaterinburg.

The urgency of works as regards protection of population and territories from natural and technogenic emergencies is supported by a decree of the President of the Russian Federation from March $23^{\text {rd }} 2000$, which establishes necessity and order of development of the system of emergencies monitoring and forecast in Russia.

\section{Aims of creation of computing system}

The computing system is intended for computer analysis of data monitoring, numerical and engineering simulation of natural and technogenic emergencies. During preparation of the works reviewed were different approaches to implementing a computing system. Multiple consultations were conducted with the relevant specialists and the employees of the services dealing with ES problems, such as the Center of Monitoring and Forecast, Central Administrative Board on CD and ES of Chelyabinsk region and others. Thus, we tried to take into account the requests, experience and specific character of the services interested in the results of this project.

In the course of the investigation it was stated that the main tasks of analysis and forecast of emergency risks are as follows:

- Revelation and identification of potential sources of natural and technogenic emergencies at a relevant territory;

- Forecast of potential consequences of damaging factors, sources of emergencies upon population and territories;

- Estimation of occurrence frequency of natural and technogenic emergencies. 


\section{Composition of computing system}

Within the computing system SC one can distinguish the following integrity of information, mathematical and methodical tools:

\subsection{Geographic and information subsystem}

Geoinformation subsystem (GIS), which serves as a tool of systematization and accumulation of disembodied and heterogeneous information, in the form of common storages of situation parameters, geography peculiarities and so on. GIS is a source of electronic cartographic, territorially binding information used in tasks of forecast, prevention and elimination of ES consequences. It includes electronic topographic territorial maps and applied software products, which allow operation with these maps. In case a location map is unavailable, a tool is provided for the manual creation of location e-schemes. Electronic and attributive information and the access means, as a part of GIS, is used as a part of computer and mathematical models of ES development, as well as in information and reference systems concerning potentially dangerous objects, forces and means for elimination of ES and their consequences.

Complexity of software and hardware tools provides access to electronic cartographic information, as a part of GIS, and its use in the information system of estimation, simulation, forecast and development of emergencies. In the source of the generation of the information part of the geoinformation subsystem developed was a database of potentially dangerous objects in relation to each other. The indicated database includes a full volume of information about enterprises, which represent potential danger (name and location of an object, an enterprise structure on the whole and particular divisions, kind and category of an object danger character, availability of dangerous substances and their quantitative characteristics, forces and means - operative available formation being involved for elimination of accident consequences and so on).

\subsection{Simulation subsystem}

The simulation subsystem includes a complex array of numerical and engineering techniques for simulating emergencies with radiation and chemical factors, whilst providing the ability of visualizing and mapping the calculation results onto a location map. In the result studied the problem was on the normative-methodical base operating in Russia as regards to the theoretical calculation of accidents consequences. The subsystem includes a number of engineering techniques for the estimation of environmental contamination under accidents with radiation and chemical factors. Let us especially note that the computing system includes the complex software of numerical simulation TREC [1] (ISTC Project № 048: "Simulation of Contamination Transfer in Atmosphere"), which is a powerful and flexible tool for the numerical simulation of environmental contamination with atmospheric discharges. It successfully combines large capabilities as for exact and detailed physical statements of a problem and reliability of numerical results. In particular, the following information can be output: 
- Contamination of a territory in any point on a map;

- Values of contamination levels by isolines;

- Areas of territories limited with each isoline;

- A list of settlements having occurred into each territory whilst indicating amount of population;

- Other information on parameters of contamination zone.

The simulation subsystem is directly connected with a meteorological satellite antenna, which allows the obtaining of reliable meteorological information in real time.

Figures 1 and 2 present an example of mapping isolines onto a location map by a technique of engineering calculation. Figure 3 presents an example of the mapping of contamination levels onto a location map with the use of the numerical simulation code "TREC".

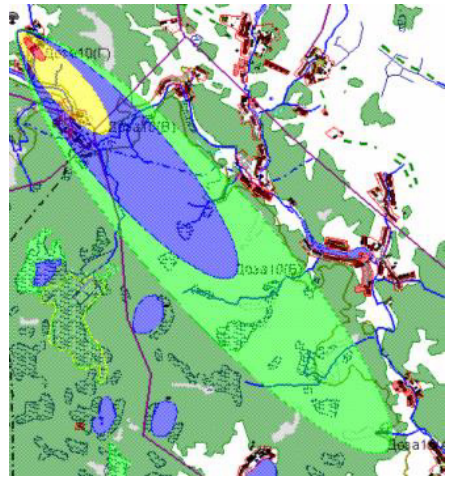

Figure 1.

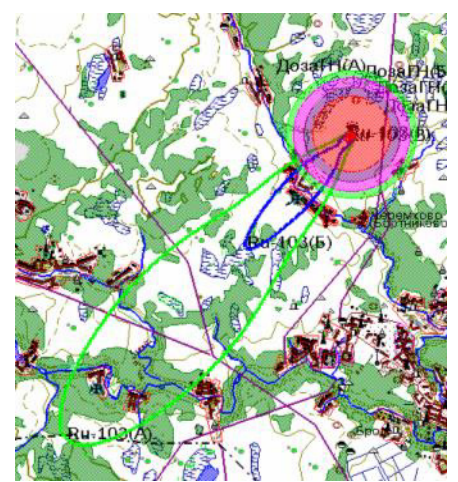

Figure 2.

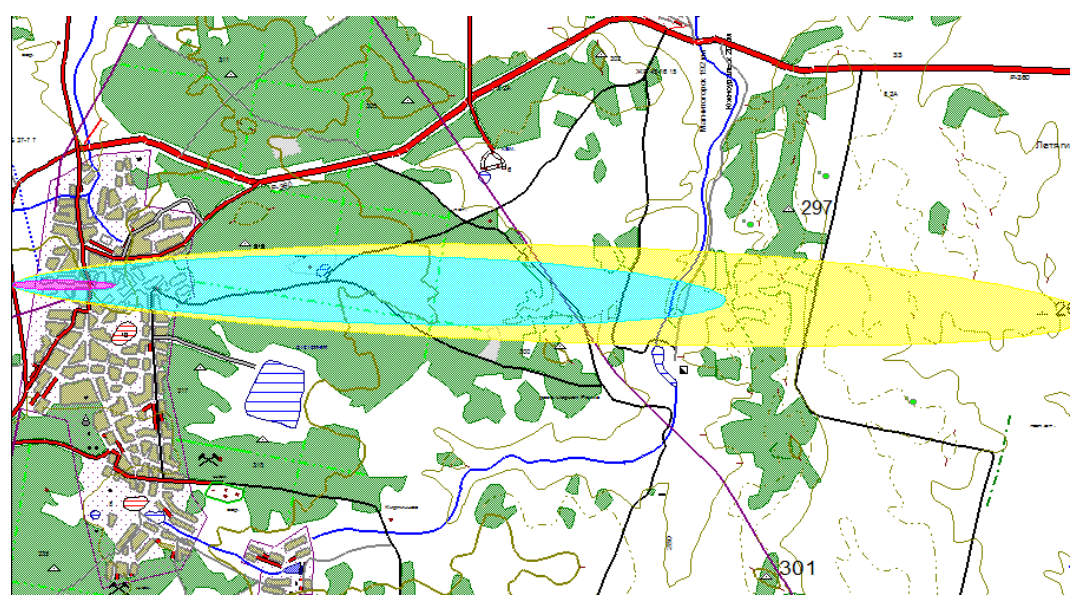

Figure 3. 


\subsection{Subsystem of ecological monitoring}

The subsystem of ecological monitoring is created for the study and analysis of ecological information with the aim to reduce the risk of emergencies occurring and to make a reasonable decision on their elimination. In RFNC-VNIITF the work under the indicated subject has already been conducted and this work was taken as a basis [2]. According to the order of RF MES on preparation and submission of GIS-based forecasts of emergencies, the subsystem performs storage and provides forecasting of natural and technogenic emergencies. Its main tasks are statistic processing of events and emergencies and construction of forecast estimation. Forecast can be performed by the six time periods:

- For a year (long-range forecast of ES);

- For a season (long-range forecast of cyclic ES);

- For a month (medium-range forecast of ES);

- For a week (short-range week forecast of ES);

- For a day (operative daily forecast);

- For a period less than 24 hours (urgent warning).

According to the calculation results the relevant information is mapped onto a location map. A location map is coloured depending on the amount, probability value and other event parameters. For vivid presentations of event parameters developed the capability is to output relevant information in the form of a diagram (fig. 4).

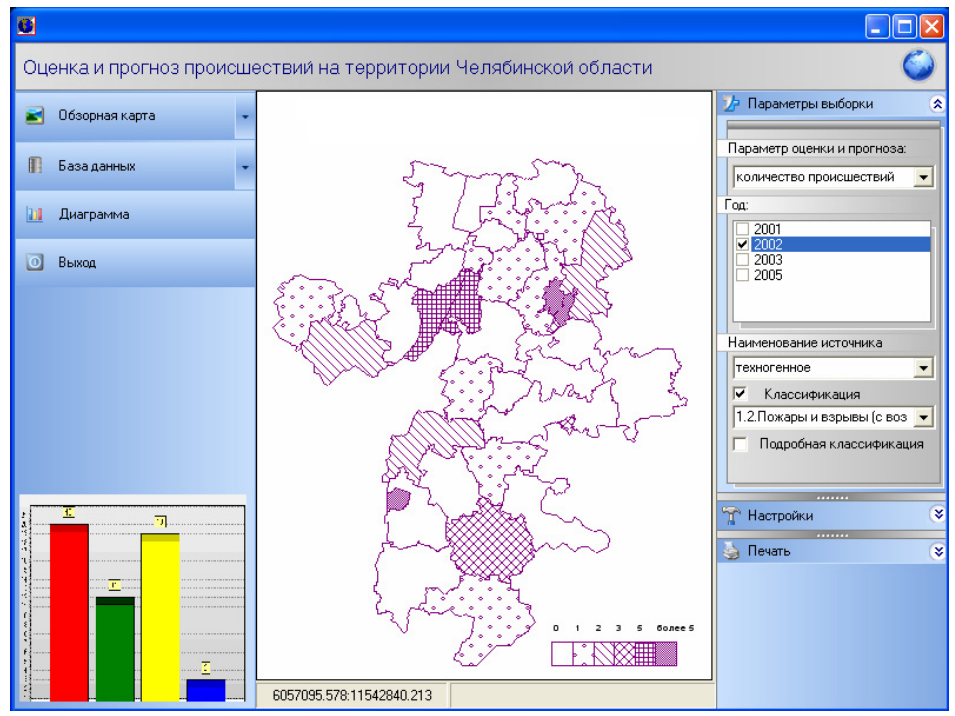

Figure 4. 


\section{Monitoring of potentially dangerous objects as a way to reduce probability of ES occurrence}

Currently, when creating large industrial sites and objects, a set of design documentation is generated, which can be considered to be a static model of a dynamic process of operation of a given object. However, in view of equipment aging, change in social and economic situation and impact of natural catastrophes, some worst-case situations not provided for a design can occur, which can lead to large accidents. One of the vivid examples of such accidents is the accident on Chernobyl APS. It can also be noted [3] that in worldwide experiences of operations in atomic industries, a peculiar place is with the accident on Industrial Association "Maiak" (Chelyabinsk region) taken place on September $29^{\text {th }}$ 1957. The accident led to large-scale contamination of environmental objects, farming lands and population exposure in considerable doses. In the result of the accident discharge of radioactive nuclides the contamination of particular territories amounted to an unprecedented level of density [3]. Therefore it is necessary to conduct continuous ecological monitoring of potentially dangerous objects accounting for changes in the environment and society. It is obvious that one should take into account a specific technological chain used on a potentially dangerous object. In this connection the following monitoring algorithm is proposed [4]:

1. System determination of region boundaries. Generalization of data about potentially dangerous objects based on design documentation, changes in society and environment.

2. Determination of a list of dangers of each of the natural catastrophes and each kind of human activity. Creation of determined-probabilistic physical models of dangerous processes and objects.

3. Ranging of potentially dangerous objects and creation of mathematical models of their operation.

4. Estimation of dangers for population under normal operation of plants, including: analysis and risk assessment of large accidents, analysis and risk estimation of toxic discharges, analysis and risk assessment of explosions, fires and so on.

5. Complex estimation for the forecast of danger of operation of potentially dangerous object accounting peculiarities of production technology, equipment aging, change in meteorological conditions and natural catastrophes.

6. Creation of a technique of calculation of ecological and economical loss because of an accident or a natural catastrophe.

This algorithm can help to determine the probability of an ecological and industrial catastrophe and in the result of mathematical simulation to provide a forecast of ecological consequences of a catastrophe in a mode advancing actual time of a catastrophe development. It should be noted that each emergency is unique. Therefore use of theory for probability and mathematical statistics cannot always lead to success. So it is necessary to develop the direction on models created under conditions of indeterminacy. 


\section{Basic results and trends}

Project results can be distributed both in complex and component-wise to different territorial structures and departments, which work in the given field. At that, it will be only required to adapt the software to actual location data and objects. It is also possible to provide services on ecological estimation of a territory and comparison of ecological and other aspects of alternative variants of performance of scheduled activities. On the whole, the complex under development provides a functional capability to enhance efficiency, accuracy and operativity of solutions of different tasks connected with the estimation and elimination of accidents, with consequences having influence upon population safety under conditions of ES threat and occurrence at objects and transport. Using the software complex the managing structures could perform analysis of ecological situation of a region and to make more efficient decisions on prevention, mitigation or compensation of impact on natural environment.

The developed software complexity is a basic operating model, which has a whole number of promising directions for expansion:

1. Creation of an expert system to perform risk assessment against possible consequences of technogenic accidents on ecologically dangerous objects under design or operating.

2. Creation of communication environment for getting operative information.

3. Creation of software for training and simulation of practical steps under potential ES.

4. Development of a tool for visualization of 3D models for buildings, rooms and their cataloging and animation.

5. Development of a tool for construction of a virtual potentially dangerous object.

In the result of implementation of the promising directions, $\mathrm{CC} \mathrm{SC}$ will be able to cover a potentially large range of tasks and to become a powerful tool in the field of ecological estimation and decisions making, that could be used not only by emergency and rescue services, situational centers and situational rooms but also by other governmental bodies responsible for ecological policy and environmental protection.

\section{References}

[1] M.I. Avramenko, E.S. Andreev, A.P. Vasiliev, V. Yu. Gusev, M. Yu. Kozmanov, V.F. Kuropatenko, E.B. Rachilov, V.A. Simonenko. Techniques and Codes for Calculating Distribution of Polydisperse Admixture in Atmosphere. Issues of Atomic Science and Technique, Series "Mathematical Modelling of Physical Processes", Issue 1, 1994, pp. 26-31.

[2] Barysheva N.M., Bukova N.A., Gavrilov A.P., Malyshev S.N., Uralshin A.G. "Fast" Estimation of Ecological Situation in Chelyabinsk Region. Information compilation, 1999, Snezhinsk, Chelyabinsk. 
188 Safety and Security Engineering II

[3] S.K. Shoigu, Consequences of Technogenic Radiation Impact and Problems of Remediation of the Ural Region. - M.: "Komtekhprint", 2002.-287pp.: ill.

[4] A.M. Grishin, Methodology of Risk-Analysis and Forecast of Catastrophes in Atomic Industry. Tomsk State University, Tomsk, 2005. 